\title{
RESEARCH
}

Open Access

\section{Evaluating the distribution of the locations of colorectal cancer after appendectomy and cholecystectomy}

Szabolcs Ábrahám ${ }^{1 * \dagger} \mathbb{1}$, Tibor Németh ${ }^{1 \dagger}$, Ria Benkő², Mária Matuz², Aurél Ottlakán, Dániel Váczi ${ }^{1}$, Attila Paszt ${ }^{1}$, Zsolt Simonka ${ }^{1}$ and György Lázár ${ }^{1}$

\begin{abstract}
Backgrounds: The number of appendectomies and cholecystectomies performed is gradually increasing worldwide. An increasing incidence of colorectal cancer (CRC) after appendectomy and cholecystectomy has been reported, but the location of tumors in certain segments of the colon and rectum after appendectomy and cholecystectomy is still uncertain. We aimed to evaluate the distribution of the locations of colorectal cancer after appendectomy and/or cholecystectomy in patients who underwent CRC surgery.
\end{abstract}

Methods: We reviewed the medical records of patients who had undergone CRC surgery between 2015 and 2017 for the presence of previous appendectomy/cholecystectomy. Data were collected from the Colorectal Data Base of the University of Szeged, Department of Surgery.

Results: Surgery for CRC was performed in 640 patients during the study period. Data of 604 patients were analyzed. Appendectomy was performed in 100 patients (16.6\%), cholecystectomy in 65 (10.8\%), and both interventions in 18 (3\%) before the CRC surgery. Out of those patients who underwent appendectomy alone, 92 (92\%) had undergone appendectomy more than 10 years before the CRC surgery. Also in these 100 patients, the prevalence of right-sided colon cancer (CC) was 35\% $(n=35)$, in comparison with the prevalence among the 504 other patients $(20.4 \%, n=103)$. The prevalence of right-sided CC among patients who underwent cholecystectomy alone was $36.9 \%(n=24)$, in comparison with $21.2 \%(n=114)$ of the 539 other patients.

Conclusions: A significant left to right side shift in CRC was noted among patients who had previously undergone appendectomy/cholecystectomy. Because right-sided CC has a worse prognosis, the role of incidental appendectomy and routine cholecystectomy seems that need re-evaluation.

Keywords: Tumor localization, Tumor, Appendectomy, Cholecystectomy, Colorectal cancer

\footnotetext{
* Correspondence: szabolcs.abraham@gmail.com; abraham.szabolcs@med.u-

szeged.hu

†'Szabolcs Ábrahám and Tibor Németh contributed equally to this work.

'Department of Surgery, Szent-Györgyi Albert Medical and Pharmaceutical Center, University of Szeged, Semmelweis u. 8., Szeged H-6725, Hungary

Full list of author information is available at the end of the article
}

(c) The Author(s). 2020 Open Access This article is licensed under a Creative Commons Attribution 4.0 International License, which permits use, sharing, adaptation, distribution and reproduction in any medium or format, as long as you give appropriate credit to the original author(s) and the source, provide a link to the Creative Commons licence, and indicate if changes were made. The images or other third party material in this article are included in the article's Creative Commons licence, unless indicated otherwise in a credit line to the material. If material is not included in the article's Creative Commons licence and your intended use is not permitted by statutory regulation or exceeds the permitted use, you will need to obtain permission directly from the copyright holder. To view a copy of this licence, visit http://creativecommons.org/licenses/by/4.0/ The Creative Commons Public Domain Dedication waiver (http://creativecommons.org/publicdomain/zero/1.0/) applies to the data made available in this article, unless otherwise stated in a credit line to the data. 


\section{Introduction}

Colorectal cancer (CRC) was the third most common malignant tumor diagnosed in 2012 worldwide (1.4 million patients) and the fourth most common cause of death (700,000 patients) [1]. CRC was responsible for approximately 150,000-175,000 deaths annually in the European Union between 2011 and 2018 [2, 3]. The incidence of CRC is expected to increase further. The incidence and rate of mortality due to CRC have increased in most of the countries except in those in which public health measures (such as CRC screening) have been initiated [1].

The prevalence of CRC shows geographical differences and is associated with the degree of industrialization in a country. The risk factors of CRC can be classified as modifiable and non-modifiable. Risk factors related to lifestyle or drug treatment include alcohol consumption, obesity, smoking, red meat consumption, sedentary lifestyle, postmenopausal hormonal treatment, nonsteroidal anti-inflammatory drug treatment $(100 \mathrm{mg}$ of acetylsalicylic acid daily), and decreased consumption of vegetables and fruits. Non-modifiable risk factors include inflammatory bowel diseases, positive family history, age, and gender [4]. Possible additional risk factors of CRC include a history of appendectomy and cholecystectomy $[5,6]$.

The average incidence of either appendicitis or appendectomy is $100-206$ per 100,000 people [7]. McVay, in 1964, was the first to observe that a significantly high percentage of patients who died of CRC had previously undergone appendectomy [8]. Later, large population cohort studies showed increased prevalence of CRC (up to 14\%) after appendectomy [5]. Cholecystectomy was also found to be associated with higher prevalence of CRC [6]. In patients who had previously undergone cholecystectomy, the incidence of CRC was 119 per 100,000, in comparison to that of 86 per 100,000 in patients who had not undergone cholecystectomy [9].

With regard to the location of $\mathrm{CRC}$, the left side of the colon is the common site in most patient population [5, $10,11]$. The location of tumors in certain segments of the colon and rectum after appendectomy and cholecystectomy is still uncertain $[5,12,13]$. Wu et al. reported that not only did patients who underwent appendectomy have an increased incidence of CRC but also the CRC location shifted [5], with increased tumor development in the rectum.

As the prognosis and survival rate of right-side $\mathrm{CC}$ is convincingly proved to be worse than left side CRC, the location of the tumor development is of utmost importance [14-17].

We aimed to evaluate the distribution of the locations of colorectal cancer after appendectomy and/or cholecystectomy in patients who underwent CRC surgery. We did not aim to analyze the causal relationship between appendectomy/cholecystectomy and development of colon cancer.

\section{Patients and methods}

The study was conducted with the ethical approval of the Ethics Committee of the University of Szeged (190/ 2015-SZTE) and the Medical Research Council (TUKEB 2655-2/2018/EKU). We gathered data from the Colorectal Data Base of the University of Szeged Department of Surgery and from the e-MedSolution ${ }^{\bullet}$ electronic integrated hospital system.

The medical histories of patients undergoing CRC surgery between 2015 and 2017 were analyzed. We sought a possible association between the location of CRCs and previous appendectomy/cholecystectomy. Patients were classified into four groups: Those in the CRC group had not previously undergone appendectomy or cholecystectomy but did have surgery for CRC, those in the CRC + APP group had previously undergone appendectomy and later surgery for CRC, those in CRC + CCY group had undergone cholecystectomy and later surgery for $\mathrm{CRC}$, and those in the CRC + APP + CCY group had undergone previous appendectomy and previous cholecystectomy and later surgery for CRC.

We conducted univariate analysis (chi-square test) to analyze the associations among different patient characteristics, CRC predisposing factors (gender, age, smoking, alcohol consumption, acetylsalicylic acid treatment (100 mg per day), history of previous CRC, family history, previous appendectomy, and cholecystectomy), and tumor main location (left colon, right colon, rectum).

The detailed distribution of CRC location (in certain colon segments) was also analyzed. Right-sided CCs were located in the caecum, ascending colon, hepatic flexure, and transverse colon, whereas left side CRCs were located the left colon segment (splenic flexure, descending colon, and sigmoid colon). Tumor location was determined by colonoscopic and abdominal computer tomography (CT) results (Fig. 1a, b).

\section{Results}

A total of 640 patients underwent surgery due to CRC. Thirty-six patients were excluded from the study (the history of appendectomy or cholecystectomy was unclear in 9 patients, bilateral synchronous tumor was present in 24 patients, and exact tumor location was unclear in 3). Data from the remaining 604 patients were statistically analyzed.

\section{General characteristics of patients}

Of the patients, 350 (57.9\%) were male; mean age was 66.5 years (standard deviation \pm 11.47 years; range, 21 to 97 years), and 336 patients (55.6\%) were older than 65 


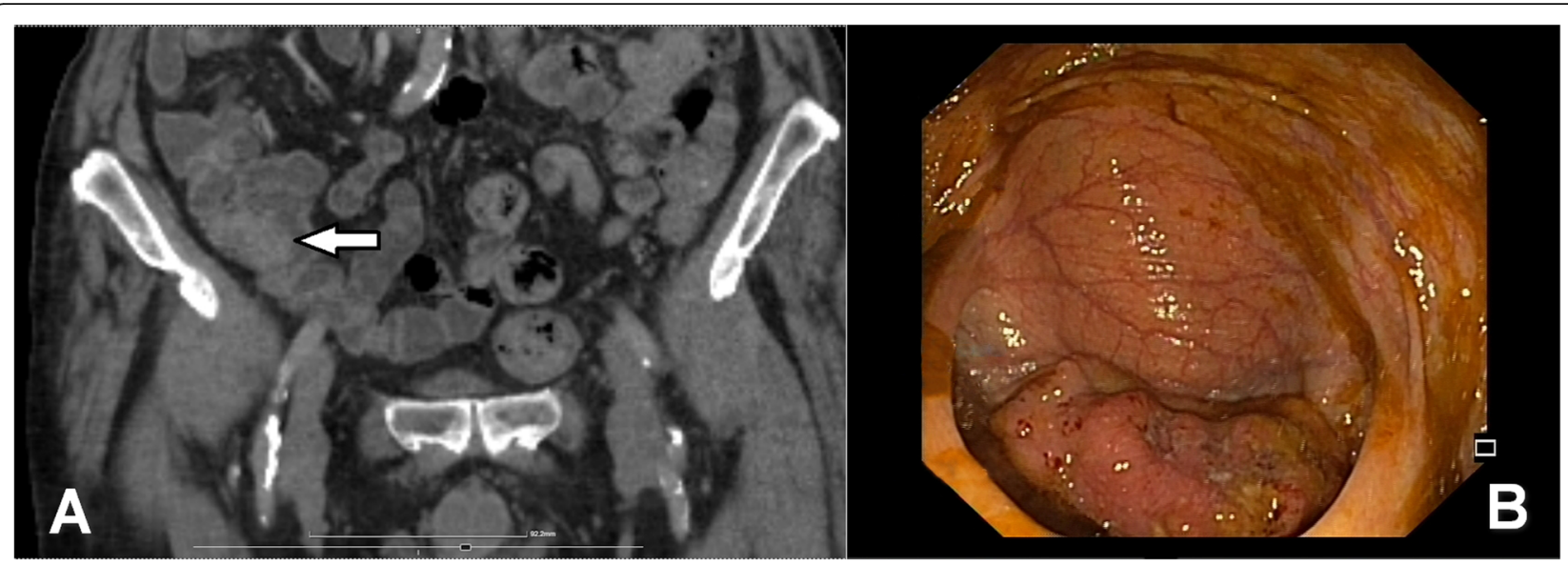

Fig. 1 a, b Abdominal computer tomography $(C T)$ and colonoscopic image of cecal cancer

years. The majority of patients did not smoke, and alcohol consumption was generally not a risk factor: 526 patients $(87.1 \%)$ had never smoked, and 78 (12.9\%) were current or former smokers. Alcohol consumption was excessive in 24 patients (4.0\%), and 90 patients (14.9\%) were taking products containing acetylsalicylic acid. Colorectal tumor was documented in the past medical history of 20 patients (3.3\%) and in the family history of 19 (3.1\%). One hundred patients (16.6\%) had previously undergone appendectomy, $65(10.8 \%)$ had previously undergone cholecystectomy, and 18 (3\%) had undergone both procedures.

\section{Colorectal cancer localization}

Tumor location was rectal in 259 patients (42.9\%), leftsided in 207 (34.3\%), and right-sided in 138 (22.8\%) of cases. Detailed examination of locations revealed that 54 patients (8.9\%) had tumors of the caecum, $29(4.8 \%)$ had tumors of the ascending colon, and $26(4.3 \%)$ had tumors of the hepatic flexure. In addition, 29 (4.8\%) had transverse colon tumors, $14(2.3 \%)$ had splenic flexure tumors, 17 (2.8\%) had tumors of the descending colon, $176(29.1 \%)$ had tumors in the sigmoid and rectosigmoid junction, and 259 (42.9\%) had rectal tumors (Table 1).

\section{Association between tumor location and different patient factors}

The findings of the associations between different patient factors and main tumor location are summarized in Table 2. CRC localization had similar distribution in the left and right colon and also the rectum among both genders (male $35.1 \% ; 20.0 \%$ and $44.9 \%$ vs female $33.1 \%$; $26.8 \%$ and $40.2 \%$ ). Those with right-sided CC were older, although age-group analysis has not revealed any statistically significant difference in the tumor localization between the two age-groups (under and above 65 years). Tumor localization did not differ in those with different lifestyle habits (smoking, alcohol consumption) or medication history with low-dose acetylsalicylic acid. Previous $\mathrm{CRC}$ in the medical or family history was also not associated with different distribution of CRC localization (Table 2).

The history of cholecystectomy or appendectomy in the medical history was associated with remarkable and statistically significant differences in tumor localization: the incidence of right-sided CC was 35\% among patients who had previously undergone appendectomy, in comparison with $20.4 \%$ among those who had not. The incidence of right-sided CC was $36.9 \%$ among patients who had previously undergone cholecystectomy, in comparison with $21.2 \%$ among those who had not.

\section{Distribution of CRC locations in different segments of the colon and rectum}

Figure 2 shows the segmental distribution of CRC locations. Overall, right-sided CC was present in 88 patients (19.3\%) in the CRC group, 17 patients $(31.9 \%)$ in the CRC + CCY group, 26 patients (31.7\%) in the CRC + APP group, and 9 patients (50\%) in the CRC + APP + CCY group. Among right-sided CCs, cecal cancers showed remarkable variations across among different patient groups: cecal cancer was present in 29 patients (6.3\%) in the CRC group, 7 patients (14.9\%) in the CRC + CCY group, 15 patients (18.3\%) in the CRC + APP group, and 3 patients (16.7\%) in the CRC + APP + CCY group. We observed an inverse tendency in the distribution of rectal cancers: we found the highest rates among those without previous appendectomy and cholecystectomy (Fig. 2).

\section{Discussion}

There are few international publications focusing on the location distribution of CRCs after gastrointestinal surgical interventions [5, 18]. In most published studies, the 
Table 1 General data of enrolled patients

\begin{tabular}{|c|c|c|}
\hline Characteristic & Number & Percentage \\
\hline \multicolumn{3}{|l|}{ Gender } \\
\hline Male & 350 & 57.9 \\
\hline Female & 254 & 42.1 \\
\hline \multicolumn{3}{|l|}{ Age } \\
\hline Mean \pm SD & $66.46 \pm 11.47$ years & \\
\hline Range & $21-97$ years & \\
\hline Above the age of 65 years & 336 & 55.6 \\
\hline \multicolumn{3}{|l|}{ Smoking } \\
\hline Smoking & 52 & 8.6 \\
\hline Quit smoking & 26 & 4.3 \\
\hline Not smoking & 526 & 87.1 \\
\hline Alcohol consumption & 24 & 4.0 \\
\hline Acetylsalicylic therapy & 90 & 14.9 \\
\hline Previous CRC & 20 & 3.3 \\
\hline Family history & 19 & 3.1 \\
\hline \multicolumn{3}{|l|}{ APP } \\
\hline In the past medical history & 100 & 16.6 \\
\hline More than 10 years earlier & 92 & 15.2 \\
\hline \multicolumn{3}{|l|}{ CCK } \\
\hline CCK in the past medical history & 65 & 10.8 \\
\hline APP and CCK together & 18 & 3.0 \\
\hline \multicolumn{3}{|l|}{ Location } \\
\hline Left side of the colon & 207 & 34.3 \\
\hline Right side of the colon & 138 & 22.8 \\
\hline Rectum & 259 & 42.9 \\
\hline \multicolumn{3}{|l|}{ Specific location } \\
\hline Caecum & 54 & 8.9 \\
\hline Ascending colon & 29 & 4.8 \\
\hline Hepatic flexure & 26 & 4.3 \\
\hline Transverse colon & 29 & 4.8 \\
\hline Splenic flexure & 14 & 2.3 \\
\hline Descending colon & 17 & 2.8 \\
\hline Sigmoid and rectosigmoid colon & 176 & 29.1 \\
\hline Rectum & 259 & 42.9 \\
\hline
\end{tabular}

Total $N=604$ patients

APP appendectomy, $C C K$ cholecystectomy, CRC colorectal cancer, SD standard deviation

investigators examined the relationship between appendectomy or cholecystectomy and CRC development, with differences in CRC incidence [6, 9, 19, 20]. After such operations, the shift in the locations of CRCs may suggest some ground of causation for these procedures.

Our results clearly confirm the predominance of rightsided CCs (i.e., an obvious left to right shift of CRC location) in those patients who have previously undergone appendectomy or cholecystectomy. According to literature, rectal and sigmoid CRCs are the most frequently seen entities, which fact is also consistent with our own results [14]. In addition to the AfricanAmerican population carrying a 1.23 relative risk of developing right-sided $\mathrm{CC}$, in comparison to the Caucasian population, the National Cancer Institute Surveillance, Epidemiology, and End Results database in the USA showed that right-sided CCs are more prevalent in elderly patients and women. Our results are consistent with this statement. The incidence of CRC proved to be higher in women and in patients older than 65 years, than in men and those younger than 65 years, respectively, although these differences were not statistically significant. Although the overall incidence of CRCs has decreased in the USA, the prevalence of right-sided CCs annually increases by $0.68 \%$, with nearly a $25.26 \%$ increase in the past 30 years [21]. Due to differences in the embryological origins of the two sides of the colon, the microbiota, histological appearance, and genetic/molecular features of right- and left-sided colon cancers differ significantly; thus, prognosis for left- and right-sided CCs varies $[11,22]$. Right-sided CC is usually diagnosed at a more advanced local stage; metastases are more likely to be present in lymph nodes showing higher tumor grade, which the results in poor prognosis and survival rate [1417].

In terms of the tumors of the colon and rectum, the shift of incidence from the left to the right side seems contradictory $[5,12]$. The predominance of right-sided $\mathrm{CC}$-especially in the caecum-was also confirmed by our study; thus, pathogenesis of CRCs may differ depending on location.

Furthermore, the effects of both previous procedures (appendectomy and cholecystectomy) may be synergistic. Factors that may potentially influence the pathogenesis of cancers after appendectomy include loss of immune function (e.g., microbiota-biofilm alterations) that can weaken the "safe house" role of the appendix [5, 23-25]. Furthermore, elapsed time since appendectomy can also play a role in tumor development. The most often emphasized factors after cholecystectomy include increased secretion of hydrophobic bile acid into the colon, dysbiosis of the microbiota, increased permeability of the colonic epithelium, increased bacterial translocation, and altered transmembrane and intracellular cascade mechanisms that influence apoptotic resistance of cells [26].

In most relevant studies, investigators have evaluated the incidence of CRCs and their location only after either appendectomy or cholecystectomy. Our study focuses on the effect of both interventions, both individually and with one another. Although the overall incidence of postcholecystectomy CRC has significantly increased in recent years, this phenomenon has not yet been proven for rectal tumors [27]. 
Table 2 Evaluation of the tumor location with univariate method

\begin{tabular}{|c|c|c|c|c|c|c|}
\hline & & Left & Right & Rectum & $\Sigma$ & Test, $p$ value \\
\hline Total & & 207 & 138 & 259 & $604(100 \%)$ & \\
\hline \multirow[t]{2}{*}{ Gender } & Male (\%) & $123(35.1 \%)$ & $70(20 \%)$ & $157(44.9 \%)$ & $350(100 \%)$ & \multirow[t]{2}{*}{ Pearson's chi-squared test; $p=0.1425$} \\
\hline & Female (\%) & $84(33.1 \%)$ & $68(26.8 \%)$ & $102(40.2 \%)$ & $254(100 \%)$ & \\
\hline \multirow[t]{4}{*}{ Age } & Mean \pm SD & $66.3 \pm 11.4$ & $70.1 \pm 11.3$ & $64.6 \pm 11.2$ & & \multirow{2}{*}{$\begin{array}{l}\text { ANOVA, } p<0.0001 \text { Tukey's multiple comparisons of means: } \\
\text { left-right } p=0.0068829 \text {; rectum-right } p=0.0000151 \text {; rectum } \\
\text { left } p=0.2394\end{array}$} \\
\hline & Min-max & $28-96$ & $41-97$ & $21-91$ & & \\
\hline & $\begin{array}{l}\text { Above the age } \\
\text { of } 65(\%)\end{array}$ & $112(33.3 \%)$ & $96(28.6 \%)$ & $128(38.1 \%)$ & $336(100 \%)$ & \multirow[t]{2}{*}{ Pearson's chi-squared test; $p$ value $=0.1736$} \\
\hline & $\begin{array}{l}\text { Maximum } 65 \\
\text { years old }\end{array}$ & $95(35.4 \%)$ & $42(15.7 \%)$ & $131(48.9 \%)$ & $268(100 \%)$ & \\
\hline \multirow[t]{3}{*}{ Smoking } & Smoking & $14(26.9 \%)$ & $7(13.5 \%)$ & $31(59.6 \%)$ & $52(100 \%)$ & \multirow[t]{3}{*}{ Pearson's chi-squared test; $p=0.05634$} \\
\hline & Quit smoking & $5(19.2 \%)$ & $5(19.2 \%)$ & $16(61.5 \%)$ & $26(100 \%)$ & \\
\hline & Not smoking & $188(35.7 \%)$ & $126(24 \%)$ & $212(40.3 \%)$ & $526(100 \%)$ & \\
\hline \multirow[t]{2}{*}{$\begin{array}{l}\text { Alcohol } \\
\text { consumption }\end{array}$} & $\begin{array}{l}\text { Regular alcohol } \\
\text { consumption }\end{array}$ & $4(16.7 \%)$ & $6(25 \%)$ & $14(58.3 \%)$ & $24(100 \%)$ & \multirow[t]{2}{*}{ Pearson's chi-squared test; $p=0.157$} \\
\hline & $\begin{array}{l}\text { No alcohol } \\
\text { consumption }\end{array}$ & $203(35 \%)$ & $132(22.8 \%)$ & $245(42.2 \%)$ & $580(100 \%)$ & \\
\hline \multirow[t]{2}{*}{$\begin{array}{l}\text { Acetylsalicylic } \\
\text { therapy }\end{array}$} & $\begin{array}{l}\text { Acetylsalicylic } \\
\text { acid intake }\end{array}$ & $25(27.8 \%)$ & $26(28.9 \%)$ & $39(43.3 \%)$ & $90(100 \%)$ & \multirow[t]{2}{*}{ Pearson's chi-squared test; $p=0.22306$} \\
\hline & $\begin{array}{l}\text { No acetylsalicylic } \\
\text { acid intake }\end{array}$ & $182(35.4 \%)$ & $112(21.8 \%)$ & $220(42.8 \%)$ & $514(100 \%)$ & \\
\hline \multirow[t]{2}{*}{ Previous CRC } & Positive & $6(30 \%)$ & $4(20 \%)$ & $10(50 \%)$ & $20(100 \%)$ & \multirow[t]{2}{*}{ Pearson's chi-squared test; $p=0.8073$} \\
\hline & Negative & $201(34.4 \%)$ & $134(22.9 \%)$ & $249(42.6 \%)$ & $584(100 \%)$ & \\
\hline \multirow[t]{2}{*}{ Family history } & Positive & $5(26.3 \%)$ & $2(10.5 \%)$ & $12(63.2 \%)$ & $19(100 \%)$ & \multirow[t]{2}{*}{ Pearson's chi-squared test; $p=0.1698$} \\
\hline & Negative & $202(34.5 \%)$ & $136(23.2 \%)$ & $247(42.2 \%)$ & $585(100 \%)$ & \\
\hline \multirow[t]{3}{*}{ APP } & Previous APP & $29(29 \%)$ & $35(35 \%)$ & $36(36 \%)$ & $100(100 \%)$ & \multirow[t]{3}{*}{ Pearson's chi-squared test; $p=0.006601$} \\
\hline & No previous APP & $178(35.3 \%)$ & $103(20.4 \%)$ & $223(44.2 \%)$ & $504(100 \%)$ & \\
\hline & $\begin{array}{l}\text { APP performed } \\
\text { more than } 10 \\
\text { years ago }\end{array}$ & $28(30.4 \%)$ & $32(34.8 \%)$ & $32(34.8 \%)$ & $92(100 \%)$ & \\
\hline \multirow[t]{2}{*}{ CCK } & Previous CCK & $16(24.6 \%)$ & $24(36.9 \%)$ & $25(38.5 \%)$ & $65(100 \%)$ & \multirow[t]{2}{*}{ Pearson's chi-squared test; $p=0.01337$} \\
\hline & No previous CCK & $191(35.4 \%)$ & $114(21.2 \%)$ & $234(43.4 \%)$ & $539(100 \%)$ & \\
\hline
\end{tabular}

CRC colorectal cancer, APP appendectomy, CCK cholecystectomy

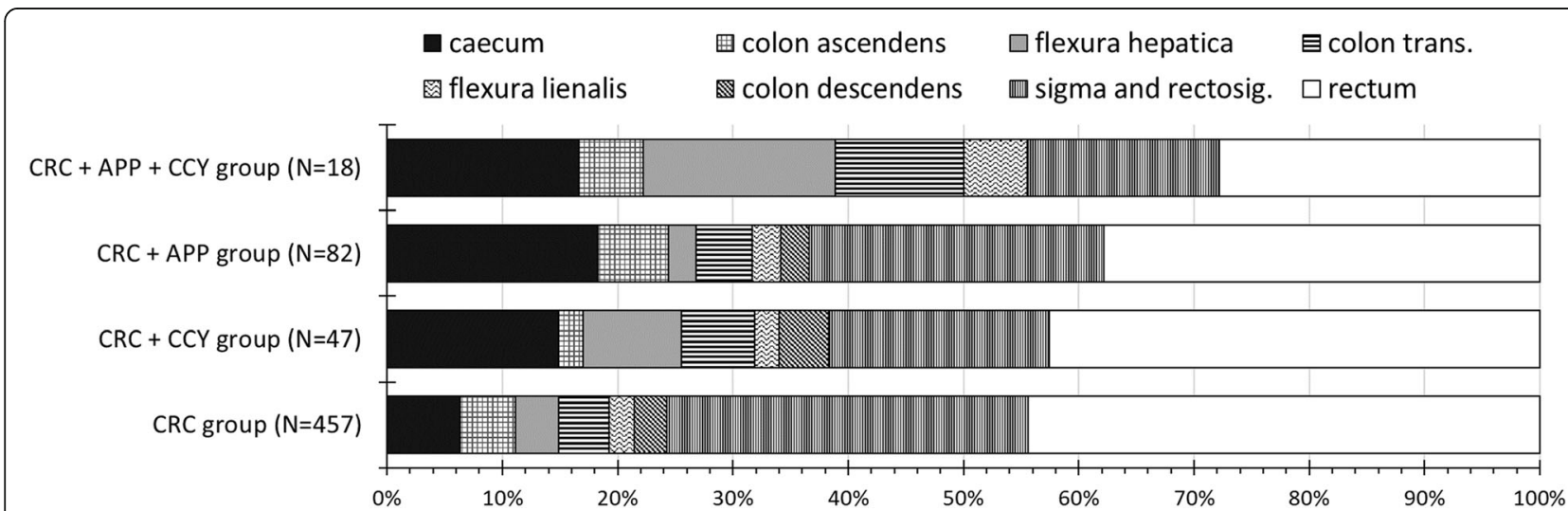

Fig. 2 Distribution of colorectal cancers in various locations. CRC, colorectal cancer surgery without previous appendectomy or cholecystectomy; $\mathrm{CRC}+\mathrm{CCY}$, colorectal cancer surgery with previous cholecystectomy; CRC + APP, colorectal cancer surgery with previous appendectomy; CRC + $\mathrm{APP}+\mathrm{CCY}$, colorectal cancer surgery with previous appendectomy and cholecystectomy 
During a 5-15-year follow-up period after appendectomy, Song et al. identified appendectomy as a risk factor in the development of right-sided CC [13]. In a retrospective study, Lee et al. found that the incidence of colon cancer $(5.74 \%)$ increased significantly during the first year after appendectomy in comparison with rectal cancer (1.89\%) [12]. In a prospective study by Wu et al., an increased incidence of CRC was seen during a 1.53.5-year follow-up period after appendectomy (with slightly increased incidence of rectal cancer) [5].

In their study including 707,663 patients, Lee et al. reported that the incidence of CRC significantly increased during the first 3 years after appendectomy, and the same phenomenon was observed 1 year after cholecystectomy [12]. In terms of elapsed time, we found that in $91.8 \%$ of patients, a more than 10 -year long time period was seen between the initial appendectomy and the development of CRC.

In the abovementioned studies, the investigators focused on the incidence of CRC after certain surgical procedures, whereas our aim was to analyze the differences in the distribution of tumor location. Our results raise further questions regarding the effects of incidental appendectomy. Incidental or prophylactic appendectomy is an intervention during which an otherwise macroscopically intact appendix is removed. It is often performed during gynecological procedures and less commonly during surgical or urological interventions. Different authors have found the rate of appendectomies without appendicitis to be between 3.6 and $47 \%$, with doubled incidence in women $[28,29]$. These results raise the question whether the number of appendectomies should be decreased both by avoiding incidental appendectomies and by forcing conservative treatment for acute uncomplicated appendicitis [30].

The indications of cholecystectomies should be narrowed down: cholecystectomy can be avoided in asymptomatic, accidentally diagnosed cases with cholecystolithiasis. Furthermore, with the assumption of a possible relationship between right-sided CC and a history of previous appendectomy or cholecystectomy, indications for incidental appendectomies and cholecystectomies should be reevaluated. The former suggestion would require further epidemiological investigations.

Our study also had some limitations. First, our analysis focused only on operated CRC cases and not on all diagnosed CRC cases. Secondly, since a single-center study, its findings cannot be directly applied to the general patient population. Thirdly, since not all CRC-associated factors (e.g., dietary factors, mental state, obesity) were assessed, this may also influence CRC location.

\section{Conclusions}

With regard to the location of CRCs, our results indicate the predominance of the right-sided colon segment (mainly the caecum) after appendectomy and cholecystectomy. The importance of the above mentioned observation is that the prognosis of right-sided CCs is worse than that of the left colon side. The indication of appendectomy and routine cholecystectomy should be considered more carefully. Further studies with control group (non-CRC) are needed to evaluate the role of appendectomy and cholecystectomy in CRCs.

\section{Abbreviations}

CRC: Colorectal cancer; CC: Colon cancer; APP: Appendectomy; CCK: Cholecystectomy; SD: Standard deviation

\section{Acknowledgements \\ None.}

Authors' contributions

$S A, D V$, and TN collected the data. SA, RB, MM, and GL analyzed the data. SA, $T N, Z S, A P, G L$, and RB interpreted the patient's data. $S A, R B, A O$, and $G L$ were major contributors in writing the manuscript. All authors read and approved the final manuscript.

\section{Funding}

No funding.

\section{Availability of data and materials}

The datasets generated and/or analyzed during the current study are not publicly available because of the data protection of the database, but are available from the corresponding author on reasonable request.

Ethics approval and consent to participate

The Ethics Committee of the University of Szeged (190/2015-SZTE) and the Medical Research Council (TUKEB 2655-2/2018/EKU) approved this study.

\section{Consent for publication}

Not applicable.

\section{Competing interests}

The authors declare that they have no competing interests.

\section{Author details}

'Department of Surgery, Szent-Györgyi Albert Medical and Pharmaceutical Center, University of Szeged, Semmelweis u. 8., Szeged H-6725, Hungary.

${ }^{2}$ Department of Clinical Pharmacy, University of Szeged, Szeged, Hungary.

Received: 16 December 2019 Accepted: 20 April 2020

Published online: 12 May 2020

\section{References}

1. Arnold M, Sierra MS, Laversanne M, Soerjomataram I, Jemal A, Bray F. Global patterns and trends in colorectal cancer incidence and mortality. Gut. 2017; 66:683-91.

2. European Commission. Eurostat population database. Luxembourg: European Union; 2020. https://ec.europa.eu/eurostat/data/database.

3. Malvezzi M, Carioli G, Bertuccio P, Boffetta P, Levi F, La Vecchia C, et al. European cancer mortality predictions for the year 2018 with focus on colorectal cancer. Ann Oncol. 2018;29:1016-22.

4. Johnson CM, Wei C, Ensor JE, Smolenski DJ, Amos Cl, Levin B, et al. Metaanalyses of colorectal cancer risk factors. Cancer Causes Control. 2013;24: $1207-22$.

5. Wu S-C. Chen WT-L, Muo C-H, Ke T-W, Fang C-W. Sung F-C. Association between appendectomy and subsequent colorectal cancer development: an Asian population study. PLoS One. 2015;10:e0118411.

6. Zhang Y, Liu H, Li L, Ai M, Gong Z, He Y, et al. Cholecystectomy can increase the risk of colorectal cancer: a meta-analysis of 10 cohort studies. PLoS One. 2017;12:e0181852.

7. Ferris M, Quan S, Kaplan BS, Molodecky N, Ball CG, Chernoff GW, et al. The global incidence of appendicitis: a systematic review of population-based studies. Ann Surg. 2017;266:237-41. 
8. Mcvay JRJ. The appendix in relation to neoplastic disease. Cancer. 1964;17: 929-37.

9. Shao T, Yang Y-X. Cholecystectomy and the risk of colorectal cancer. Am J Gastroenterol. 2005;100:1813-20.

10. Jung M-K, Shin US, Ki Y-J, Kim Y-B, Moon S-M, Sung S-J. Is the location of the tumor another prognostic factor for patients with colon cancer? Ann Coloproctol. 2017;33:210-8.

11. Benedix F, Schmidt U, Mroczkowski P, Gastinger I, Lippert H, Kube R. Colon carcinoma-classification into right and left sided cancer or according to colonic subsite?-analysis of 29,568 patients. Eur J Surg Oncol. 2011;37:134-9.

12. Lee J, Choe S, Park JW, Jeong S-Y, Shin A. The risk of colorectal cancer after cholecystectomy or appendectomy: a population-based cohort study in Korea. J Prev Med Public Health. 2018;51:281-8.

13. Song $\mathrm{H}$, Abnet CC, Andren-Sandberg A, Chaturvedi AK, Ye W. Risk of gastrointestinal cancers among patients with appendectomy: a large-scale Swedish register-based cohort study during 1970-2009. PLoS One. 2016;11: e0151262.

14. Benedix F, Kube R, Meyer F, Schmidt U, Gastinger I, Lippert H. Comparison of 17,641 patients with right- and left-sided colon cancer: differences in epidemiology, perioperative course, histology, and survival. Dis Colon Rectum. 2010:53:57-64.

15. Yamauchi M, Morikawa T, Kuchiba A, Imamura Y, Qian ZR, Nishihara R, et al. Assessment of colorectal cancer molecular features along bowel subsites challenges the conception of distinct dichotomy of proximal versus distal colorectum. Gut. 2012;61:847-54.

16. Suttie SA, Shaikh I, Mullen R, Amin Al, Daniel T, Yalamarthi S. Outcome of right- and left-sided colonic and rectal cancer following surgical resection. Colorectal Dis. 2011;13:884-9.

17. Yahagi M, Okabayashi K, Hasegawa H, Tsuruta M, Kitagawa Y. The worse prognosis of right-sided compared with left-sided colon cancers: a systematic review and meta-analysis. J Gastrointest Surg. 2016;20:648-55.

18. Chen C-H, Lin C-L, Kao C-H. The effect of cholecystectomy on the risk of colorectal cancer in patients with gallbladder stones. Cancers (Basel). 2020; 12:pii: E550.

19. Meng W, Cai S-R, Zhou L, Dong Q, Zheng S, Zhang S-Z. Performance value of high risk factors in colorectal cancer screening in China. World J Gastroenterol. 2009;15:6111-6.

20. Zhao C, Ge Z, Wang Y, Qian J. Meta-analysis of observational studies on cholecystectomy and the risk of colorectal adenoma. Eur J Gastroentero Hepatol. 2012;24:375-81.

21. Lee GH, Malietzis G, Askari A, Bernardo D, Al-Hassi HO, Clark SK. Is rightsided colon cancer different to left-sided colorectal cancer? - a systematic review. Eur J Surg Oncol. 2015;41:300-8.

22. Baek SK. Laterality: right-sided and left-sided colon cancer. Ann Coloproctol. 2017;33:205-6.

23. Kooij IA, Sahami S, Meijer SL, Buskens CJ, Te Velde AA. The immunology of the vermiform appendix: a review of the literature. Clin Exp Immunol. 2016;186:1-9.

24. Enblad M, Birgisson H, Ekbom A, Sandin F, Graf W. Increased incidence of bowel cancer after non-surgical treatment of appendicitis. Eur J Surg Oncol. 2017:43:2067-75

25. Cope JU, Askling J, Gridley G, Mohr A, Ekbom A, Nyren O, et al. Appendectomy during childhood and adolescence and the subsequent risk of cancer in Sweden. Pediatrics. 2003;111:1343-50.

26. Hegyi P, Maleth J, Walters JR, Hofmann AF, Keely SJ. Guts and gall: bile acids in regulation of intestinal epithelial function in health and disease. Physiol Rev. 2018;98:1983-2023.

27. Coats M, Shimi SM. Cholecystectomy and the risk of alimentary tract cancers: a systematic review. World J Gastroenterol. 2015;21:3679-93.

28. Song JY, Yordan E, Rotman C. Incidental appendectomy during endoscopic surgery. JSLS-J Soc Laparoend. 2009;13:376-83.

29. Man E, Nemeth T, Geczi T, Simonka Z, Lazar G. Learning curve after rapid introduction of laparoscopic appendectomy: are there any risks in surgical resident participation? World J Emerg Surg. 2016;11:17.

30. Salminen P, Tuominen R, Paajanen H, Rautio T, Nordstrom P, Aarnio M, et al. Five-year follow-up of antibiotic therapy for uncomplicated acute appendicitis in the APPAC randomized clinical trial. JAMA. 2018;320:1259-65.

\section{Publisher's Note}

Springer Nature remains neutral with regard to jurisdictional claims in published maps and institutional affiliations.

Ready to submit your research? Choose BMC and benefit from:

- fast, convenient online submission

- thorough peer review by experienced researchers in your field

- rapid publication on acceptance

- support for research data, including large and complex data types

- gold Open Access which fosters wider collaboration and increased citations

- maximum visibility for your research: over $100 \mathrm{M}$ website views per year

At BMC, research is always in progress.

Learn more biomedcentral.com/submissions 